\title{
Diversity Management: An Organisational Culture Audit To Determine Individual Differences
}

\author{
Prof Ophillia Ledimo, University of South Africa, South Africa
}

\begin{abstract}
The purpose of this study was to conduct an organisational culture audit to determine individual differences of employees within the South African army. A quantitative study was conducted with a random sample size $n=238$. The participants completed the biographical questionnaire and the Organisational Culture Inventory (OCI) which was used to measure organisational culture. Descriptive and inferential statistics were used to identify the existing culture type in this organisation and the statistically significant individual differences of the employees regarding their perception of the organisational culture. The findings of this study are valuable for organisational development practitioners and managers who are responsible to manage diversity in their organisation because it enables organisations to understand the culture of their diverse workforce and to propose relevant measures for improving employee performance using individual differences. These findings also provide opportunity for future research. This study also adds knowledge regarding organisational culture diagnosis and the nature of individual differences, especially within the South African work context.
\end{abstract}

Keywords: Organisational Culture; Diversity; Individual Differences; Demographic

\section{INTRODUCTION}

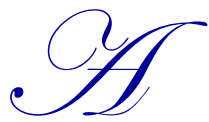

diverse workforce is a reflection of a changing world and marketplace (Mazur, 2010). Thus, managing diversity is an important aspect of leadership in today's multi-cultural work context. Organisations are becoming diverse because of the increasing globalization that requires more interaction among people from diverse cultures, beliefs, and backgrounds than ever before (Wrech, 2005; Mazur, 2010; Werner, 2007). Thomas (1996) also highlighted that diversity in organisations has for too long been associated with multicultural, multiethnic and multiracial aspects of the workforce. An increasing number of organisations are attempting to enhance inclusiveness of under represented individuals through proactive efforts to manage their diversity (Gilbert, Stead and Ivancevich, 1999).

Preissing and Loennies (2011) indicate that the culture of an organisation tends to view the individual employee as an important component as there is a dynamic and reciprocity of its development within and outside the organisational context and the development of an organisational culture. Studies conducted on organisational culture found that culture is important in understanding employee behaviour and performance (Brown, 1998; Robbins, 1996; Werner, 2007). Hence organisations that are faced with the challenge of managing a diverse workforce would need to assess their organisational culture in order to develop knowledge of the existing organisational culture differences among their employees. Failure to manage diversity in the organisation might become an obstacle for achieving organisational goals. Managing and valuing diversity is a key component of effective people management, which can improve the productivity of the organisation (Gilbert et al, 1999; Mazur, 2010). As a result maximizing and capitalizing on workplace diversity has become an important issue for management today.

In the search to find strategies to manage a diverse workforce in organisations, it would be beneficial to gain insight into the relationship between individual differences and organisational culture; with a specific focus on 
how race, job levels and age groups differ. Therefore, the current research study examined how individual differences influence employees' perceptions of their organisational culture.

\section{LITERATURE REVIEW}

The following literature reviews described the variables individual difference, organisational culture and the theoretical relationship between these variables.

\section{Individual Differences}

Individuals differ from each other in some way or the other; hence such a similarity or difference between persons reveals individual differences. This suggests that a group of employees is diverse if it is composed of individuals who differ on a characteristic on which they base their own social identity (Robbins, 2005; Werner, 2007; O'Reilly, Williams and Barsade, 1998). Hence diversity is described as any mixture of items characterised by differences and similarities (Thomas 1996). Individual differences refer to the extent and kind of variations or similarities among people on some aspects such as demographic factors. They are essential in understanding employees within an organisation. Studies have been conducted to indicate the role of individual differences such as gender, age and race group in relation to organisational variables; namely, culture, commitment, retention, career development, work engagement, job satisfaction, performance and job embeddedness (Manetje and Martins 2009; Tanova and Holtom, 2008; Lumley, 2009; Martin and Roodt, 2008; Muteswa and Ortlepp, 2011). These studies reported that there are statistically significant individual differences based on the variables gender, age and race group.

There are primary and secondary dimensions of individual differences. According to Mazur (2010) the primary dimensions of individual differences that exert primary influences on employees' identities, are gender, ethnicity, race, sexual orientation, age and mental or physical abilities and characteristics. These primary dimensions shape employees' basic self-image as well as their fundamental world views (Thomas, 1996; Wrech, 2005; Mazur, 2010). The secondary dimensions of individual differences are less visible; they exert a more variable influence on personal identity and add a more subtle richness to the primary dimensions of diversity (Wee, Jonason and Li, 2014; Mazur, 2010). These dimensions include; namely, educational background, geographic location, religion, first language, family status, work style, work experience, military experience, organisational role and level, income and communication style. The primary and secondary dimensions of individual differences occur due to interaction of genetic and environmental factors. This implies that employees have inherited certain characteristics through genetic codes, such as race. Both the primary and secondary dimensions may intertwine to produce unique syntheses of human profiles, made up of both differences and similarities (Mazur, 2010). Hence it is important to identify and understand this uniqueness in individuals because they are important for diversity management. According to Wrech (2005) diversity management stresses the necessity of recognizing individual and cultural differences between groups of employees, and making practical allowances for such differences in organisational policies.

Organisations need diversity to become more creative and open to change (Martin and Roodt, 2008; Mazur, 2010). Encouraging a diverse workplace where individual differences are valued enables employees to work to their full potential in a more creative and productive work environment (DeNisi and Griffin, 2008; Wrech, 2005). This is seen as an inclusive approach of diversity management; the one which therefore encompasses the interests of all employees in the organisation. Mazur (2010) indicated that organisations need to focus on diversity and look for ways to become totally inclusive organisations because diversity has the potential of yielding greater productivity and competitive advantages. Ivancevich and Gilbert (2000) argued that diversity management leads to an increased understanding of diverse customers, increased creativity and commitment to the organisation, and better retention and attendance. According to Mazur (2010) respecting individual differences will benefit the organisation by creating a competitive edge and increasing work productivity.

\section{Organisational Culture}

The concept organisational culture has various definitions, predominantly in the context of psychology and management theory (Struwig and Smith, 2002; Robbins, 2005; Hampden-Turner, 1990). Bagraim (2001) states that 
there is no single universally accepted definition of the term organisational culture, hence there is a variety of definitions. A basic definition of organisational culture is necessary to provide a point of departure in the quest for an understanding of the phenomenon. Martins and Martins (2003) define organisational culture as a system of shared meaning held by members, distinguishing the organisation from other organisations. This implies that culture is an integrated pattern of human bevahoir which is unique to a particular organisation.

Organisational culture also refers to a pattern of basic assumptions invented, discovered, or developed by a given group as it learns to cope with its problems of external adaptation and internal integration that has worked well enough to be considered valid, and therefore, to be taught to new members as the correct way to perceive, think, and feel in relation to those problems (Schein, 1985; Hofstede, 1991; Harris and Ogbonna, 1998; Manetje and Martins, 2009). Culture includes distinctive norms, beliefs, principles and ways of behaving that are combined to give each organisation its distinct character (Arnold, 2005; Johnson, 1990; Cummings and Worley, 2005). This suggests that organisational culture distinguishes one organisation from another organisation; it is therefore to an organisation what personality is to an individual.

The literature is abundant regarding the types and dimensions of organisational culture. Deal and Kennedy (1982) identified four generic types of cultures to describe organisational culture; namely, the tough-guy/macho culture, the work-hard/play-hard culture, the bet-your company culture and the process culture. Handy (1985) described organisational culture by using four types of classification; namely, power, role, task and person cultures. Schein (1985) used three levels to explain organisational culture; namely, artefacts, values and basic underlying assumptions. Scholtz (1987) identified five primary culture typologies; namely, stable, reactive, anticipating, exploring and creative. Hampden-Turner (1990) used four types of culture to describe organisational culture; namely, role, power, task and atomistic cultures. Hofstede (1991) highlighted that cultures differ based on five dimensions, namely power distance, individualism/collectivism, uncertainty avoidance, masculinity/femininity and confusion dynamism. O'Reilly, Chatman and Caldwell (1991) presented seven primary characteristics to describe organisational culture; namely, innovation and risk-taking, attention to detail, outcome orientation, people orientation, team orientation aggressiveness and stability.

These various typologies of organisational culture indicate that culture is described and conceptualised differently in the literature. According to Wee et al (2014) the types of organisational culture have a distinct system of shared meaning; which is a common way of interpreting actions and events that does not always hold across individuals and groups. Cooke and Lafferty (1998) also identified the following three types of culture that are relevant for this study because the typologies have corresponding sets of behavioural norms. Firstly, constructive culture dimension implies that employees are encouraged to interact with others and approach tasks in the manner that will help them meet their higher-order satisfaction needs, and are characterised by achievements, selfactualising, humanistic-encouraging and affiliation. Secondly, passive/defensive culture dimension means that employees believe they must interact with people in ways that will not threaten their own security, and are characterised by the approval, conventional, dependent and avoidance styles. Lastly, aggressive/defensive culture indicates that employees are expected to approach tasks in forceful ways to protect their status and security, and are characterised by the oppositional, power, competitive and perfectionist styles.

Organisational culture is important in organisations because it refers to created assumptions, which are accepted as a way of doing things and are passed on to new members of an organisation. For new employees this would mean adaptive behaviour within the organisation that leads to new belief systems. This new and adaptive behaviour is instilled through organisational values and beliefs that are associated with rituals, myths and symbols to reinforce the core assumptions of organisational culture (Hofstede, 1991; Martins and Martins, 2003). Brown (1998) highlighted that culture as the pattern of beliefs, values and learned ways of coping with experience that have developed during the course of an organisation's history; it tends to be manifested in its material arrangements and in the behaviours of its members. This suggests that organisational culture is articulated in the organisation, in order to shape the way in which organisational members should behave. However, this pattern of values, norms, beliefs, attitudes, principles and assumptions may be unwritten or non-verbalised behaviour that describe the way in which things get done; to give the organisation its unique character (Williams and Barsade, 1998; Robbins, 2005; Brown, 1998; Arnold, 2005). 
The benefits of culture in organisations are that it directs the organisation towards goal attainment, organisational success, enhances organisational citizenship, loyalty, customer satisfaction, motivation and it increases the consistency of employees' behaviour (Martins and Von der Ohe, 2006; Martins and Martins, 2003; Robbins, 2005; Struwig and Smith, 2002; Pressing and Loennies, 2011). Ivancevich, Konopaske and Matterson (2005) argued that culture influences employees to be good citizens and cooperate in the organisation. Culture is able to create a unifying force that increases organisational performance and it is able to positively affect employee behaviour and the financial performance of the organisation (Davidson, 2003; Manetje and Martins, 2009; Ivancevich et al, 2005; Werner, 2007; Mazur, 2010). Martins, Martins and Terblanche (2004) highlighted that organisational culture complements rational managerial tools such as strategy, goals, tasks, technology, organisational structure, information systems and performance appraisal; by playing an indirect role in influencing employee behaviour. Some of the studies conducted in various South African organisations indicate that organisational culture contributes towards employees' job satisfaction and organisational commitment (Sempane, Rieger and Roodt, 2002; Manetje and Martins, 2009).

\section{Theoretical Relationship Between Organisational Culture and Individual Differences}

Organisations are consistently focussing on their systematic and planned commitment to recruit, retain, reward, and promote a heterogeneous mix of employees (Ivancevich and Gilbert, 2000; Cummings and Worley, 2005). According to Wee et al (2014) different interpretations of organisational culture become increasingly likely as the work context becomes increasingly multi-cultural, more ethnically diverse workforces within organisations. The different interpretations of culture by employees tend to lead to the development of dominant and sub-cultures in the organisation. Hence individual differences are considered to be the source of sub-cultures. A sub-culture emerges as a result of a subgroup's collective functionality in a specific unit of the organisation (Robbins, 2005). It occurs as a result of individual experiences concerning certain aspects in organisations. The sub-culture could be efficient and appropriate if it is not contradicting the dominant or ideal organisational culture.

While large organisations have a dominant organisational culture, they are at risk of developing a number of sub-cultures. Sub-cultures tend to develop in large organisation to reflect common problems, situations and experiences faced by employees in the organisation (Martins and Von der Ohe, 2006). Organisations develop subcultures because of functional differences, gender, socio-economic and educational backgrounds (Deal and Kennedy, 1982). Sub-cultures exist independently of organisational culture and a small group may have its own distinct set of values, beliefs and attitudes (Lok and Crawford, 1999). Martins and Von der Ohe (2006) argued that variables that play a role in the formation of sub-cultures are departmental groupings, race groups, geographical distribution, occupational categories or the influence of a specific manager. This implies that individual differences have an influence in the creation or development of sub-cultures within the organisation.

Military organisations are large in nature and they are at the risk of having sub-cultures. The challenge of having sub-cultures in the organisation is due to the different effects a subculture have on individuals in the organisation. Hence this study is motivated by the need to gain a better insight into the effects of demographic factors or individual differences (race, age and job level) on the three dimensions of organisational culture; in order to indicate to policymakers and managers where improvements can be made, and to helps them to develop strategies and policies that could create an ideal organisational culture and to manage diversity. There is therefore a perceived need to augment the South African literature base regarding individual differences, diversity management and organisational culture in particular.

Based on the above motivation and the literature review, the main purpose of this study is to determine individual differences that influence employees' perceptions of their organisational culture in the South African Army. The following hypothesis was formulated for this study.

Hypothesis: There are statistically significant individual differences regarding the participants' perception of the organisational culture. 


\section{RESEARCH DESIGN AND METHOD}

\section{Research Approach}

A quantitative design was followed in this study in order to achieve the research objectives of the empirical study (Kerlinger, 1986). Survey methodology was used to collect primary data from a random sample of participants.

\section{Participants and Sampling Strategy}

The total population of the study comprised of 4350 employees of the military organisation. Simple random sampling technique was used to ensure that all employees within the department had an equal chance to be included in the sample (Keller and Warrack, 2000). The 238 participants of this study who are employed at managerial and staff level, were randomly selected by means of a computerised program. They were from various divisions and directorates within the army. All participants received the questionnaire with a covering letter from the researchers which introduced the study and explained its purpose. It also included instructions for completing and returning the questionnaire upon completion, the method for participant's selection, anonymity and confidential nature of the research process.

\section{Measuring Instruments}

Section A of the questionnaire comprised of the biographical questionnaire which measured individual differences as the independent variables; namely, age, gender, highest qualification, years of service, job level and race groups. The majority of the participants who completed the questionnaires were aged 35 above (58\%) and the sample was predominantly represented by males $(61.1 \%)$ rather than females. In terms of race, Africans $(65.9 \%)$ were the majority. The different race groups included Asian (7\%), coloureds (9.7\%) and whites (22.7\%) participants. Most of the participants had Grade $12(60.5 \%)$ as the highest qualification and had been with the organisation for more than 10 years $(65.50 \%)$. In terms of job levels, most participants were at the operational staff level $(69 \%)$ while the participants that were employed at the managerial level were less $(31 \%)$.

Sections B included the Organisational Culture Inventory (OCI) which was used to measure the dependent variable organisational culture (Cooke and Szumal, 1993). The OCI was designed by Cooke and Lafferty (1987) with the aim of measuring behavioural norms within an organisational setting. Cooke and Szumal (2000) stated that since its introduction, the OCI has been used by thousands of organisations and completed by over 2 million respondents throughout the world. The behavioural norms are grouped into three types or dimensions of organisational culture; namely, constructive, passive/defensive and aggressive/defensive dimensions (Cooke and Szumal, 1993). Xenikou and Furnham (1996) reported that the reliability for the organisational culture dimensions ranged from 0.89 to 0.95 . Hence the psychometric property of the OCI was considered sufficient for this study.

\section{FINDINGS}

The following discussion of the results of this study focusses on the descriptive statistics, reliability and the One-way Analysis of Variance (ANOVA).

\section{Descriptive Statistics and Reliability of the Organisational Culture Inventory}

The Cronbach's alpha coefficients were used in this study to determine the reliability of the measuring instrument, namely the OCI. Terre Blanche and Durrheim (1999) state that a Cronbach's alpha coefficient that ranges from 0 means there is no internal consistency, while a score of 1 is the maximum internal consistency score. This suggests that the higher the alpha coefficient, the more reliable the measuring instruments. A Cronbach's alpha coefficient of 0.75 is regarded as a desirable reliability coefficient (Terre Blanche and Durrheim, 1999). Table 1 presents the Cronbach's alpha values, mean scores and the standard deviations of the OCI. The Cronbach's alpha for the OCI ranges from 0.867 to 0.964 for the three dimensions, which is regarded as desirable. 
Table 1. Descriptive statistics and reliability of the Organisational Culture Inventory dimensions

\begin{tabular}{lcccc}
\hline \multicolumn{1}{c}{ OCI Dimensions } & Cronbach's alpha coefficient & Mean & SD & Number of items \\
\hline Constructive & 0.964 & 114.38 & 25.77 & 32 \\
Passive/Defensive & 0.867 & 102.06 & 16.62 & 32 \\
Aggressive/Defensive & 0.873 & 98.29 & 18.47 & 32 \\
$n=238 ; S D=$ Standard deviation & & & &
\end{tabular}

In terms of the mean and the standard deviations as the measures of internal consistency; table 1 indicates that the constructive culture dimension has the highest mean $(\mathrm{m}=114.38)$ with a standard deviation of 25.77 . The aggressive/defensive culture dimension has the lowest mean of 98.29 with a standard deviation of 18.47. This result implies that the employees perceive the constructive organisational culture as the most dominant culture in the organisation; when compared with the aggressive/defensive and passive/defensive.

\section{One-Way Analysis of Variance (ANOVA): Organisational Culture Inventory and Individual Differences}

The ANOVA was conducted for this empirical study to determine whether there are statistically significant differences between the independent variable individual differences and the dependent variable organisational culture. The following individual differences variables were used as the independent variables; namely, race, job level and age.

Table 2. ANOVA of Organisational Culture Inventory and Race

\begin{tabular}{llcc}
\hline \multicolumn{1}{c}{ OCI Dimensions } & F & Significance \\
\hline Constructive & Between groups & 2.840 & $0.039^{*}$ \\
Passive/Defensive & Between groups & 1.777 & 0.153 \\
Aggressive/Defensive & Between groups & 1.851 & 0.140 \\
\hline
\end{tabular}

$* * \mathrm{p}<0.01 ; * \mathrm{p}<0.05$

The results presented in table 2 , indicates that the statistically significant difference was only found between the variable race and the participants' perception of the Constructive culture dimension $(\mathrm{p}<0.05)$ as the dominant organisational culture. However, there are no statistically significant difference between the independent variable race and the organisational culture dimensions Passive/Defensive and Aggressive/Defensive.

Table 3. Mean scores for Organisational Culture Inventory and race groups

\begin{tabular}{ccccc}
\hline OCI Dimensions & Race & Mean & Standard deviation & Standard error \\
\hline Constructive & African & 116.43 & 26.52 & 2.432 \\
& Asian & 100.00 & 26.87 & 19.000 \\
& Coloured & 121.16 & 19.60 & 4.498 \\
& White & 105.66 & 22.81 & 3.328 \\
\cline { 2 - 5 } & Overall score & $\mathbf{1 1 4 . 0 3}$ & $\mathbf{2 5 . 3 9 4}$ & $\mathbf{1 . 8 5 7}$ \\
\hline
\end{tabular}

In addition, the mean results in table 3 indicate that coloured employees in this organisation obtained a significantly higher mean score for the Constructive culture dimension $(\mathrm{m}=121.16)$ compared to the other race groups; namely, African $(\mathrm{m}=116.43)$, whites $(\mathrm{m}=105.66)$ and Asian $(\mathrm{m}=100.00)$. Although all the race groups rated the Constructive organisational culture dimension the highest, the coloured participants of this organisation viewed the culture of the organisation as more Constructive to a larger extent than the other three races groups.

Table 4. ANOVA of the Organisational Culture Inventory and Age

\begin{tabular}{llcc}
\hline \multicolumn{1}{c}{ OCI Dimensions } & Groups & F & Significance \\
\hline Constructive & Between groups & 3.712 & $0.006^{* *}$ \\
Passive/Defensive & Between groups & 0.589 & 0.671 \\
Aggressive/Defensive & Between groups & 2.139 & 0.078 \\
\hline$* * \mathrm{p}<0.01 ; * \mathrm{p}<0.05$ & & & \\
\hline
\end{tabular}


According to Table 4, the results report that statistically significant differences were found between the variable age and the participants' perception of the Constructive dimension $(\mathrm{p}<0.01)$ as the dominant organisational culture. Still, there are no statistically significant difference between the independent variable age and the organisational culture dimensions Passive/Defensive and Aggressive/Defensive.

Table 5. Mean scores for Organisational Culture Inventory and age groups

\begin{tabular}{lcccc}
\hline OCI Dimensions & Age group & Mean & Standard deviation & Standard error \\
\hline Constructive & 24 and younger & 126.78 & 18.06 & 2.856 \\
& $25-34$ & 111.67 & 27.50 & 5.614 \\
& $35-44$ & 110.24 & 26.28 & 3.142 \\
& $45-52$ & 111.84 & 26.16 & 3.901 \\
& 53 and older & 102.67 & 19.87 & 6.625 \\
\hline
\end{tabular}

The results in table 5 illustrates that the participants younger than 24 years in age in this organisation obtained a significantly higher mean score for the Constructive culture dimension $(\mathrm{m}=126.78)$ compared to the other age groups. The reported means score for the other age groups indicate the mean scores of 111.67 (25-34 years); 110.24 (35- 44 years); 111.84 ( $45-52$ years) and 102.67 (53years and older). This implies that young employees in this organisation perceive the Constructive organisational to be dominant when compare with older employees.

Table 6. ANOVA of the Organisational Culture Inventory and job level

\begin{tabular}{llcc}
\hline \multicolumn{1}{c}{ OCI Dimensions } & F & Significance \\
\hline Constructive & Between groups & 3.163 & 0.077 \\
Passive/Defensive & Between groups & 6.016 & $0.015^{*}$ \\
Aggressive/Defensive & Between groups & 12.001 & $0.001 * *$ \\
\hline$* * \mathrm{p}<0.01 ; * \mathrm{p}<0.05$ & & & \\
\hline
\end{tabular}

Table 6 indicates that statistically significant differences were found between the variable job level and the participants' perception of the Passive/Defensive $(\mathrm{p}<0.05)$ and Aggressive/Defensive $(\mathrm{p}<0.01)$ as the dominant organisational cultures. However, there are no statistically significant difference between the independent variable job level and the Constructive organisational culture dimension.

Table 7. Mean scores for Organisational Culture Inventory and job levels

\begin{tabular}{clccc}
\hline OCI Dimensions & \multicolumn{1}{c}{ Position } & Mean & Standard deviation & Standard error \\
\hline \multirow{3}{*}{ Passive/Defensive } & Managers & 99.10 & 16.393 & 1.728 \\
& Operational staff & 105.02 & 16.428 & 1.685 \\
& Overall scores & $\mathbf{1 0 2 . 1 4}$ & $\mathbf{1 6 . 6 3 3}$ & $\mathbf{1 . 2 2 3}$ \\
\hline \multirow{3}{*}{ Aggressive/Defensive } & Managers & 93.74 & 15.688 & 1.636 \\
& Operational staff & 102.31 & 17.332 & 1.869 \\
& Overall scores & $\mathbf{9 7 . 8 8}$ & $\mathbf{1 7 . 0 0 8}$ & $\mathbf{1 . 2 7 5}$ \\
\hline
\end{tabular}

The results in table 7 indicates that the participants who are employed as operational staff in this organisation obtained a significantly higher mean score for the Passive/Defensive culture dimension $(\mathrm{m}=105.02)$ when compared to their managers $(m=99.10)$. Similarly, the results shows that participants who are employed as operational staff in this organisation obtained a significantly higher mean score for the Aggressive/Defensive culture dimension $(\mathrm{m}=102.31)$ when compared to their managers $(\mathrm{m}=93.74)$.

\section{DISCUSSION}

Overall, the results showed that the participants differed significantly regarding their perception of the organisational culture based on the independent variables race, job level and age groups. This result suggests that it is important to consider individual differences because culturally shared values and beliefs shape the way people construct their reality (Wee et al, 2014). This findings support Martins and Von der Ohe (2006) proposition that individual differences regarding the organisational culture subsequently leads to the creation of sub-cultures in the organisation. This implies that the demographic variables such as gender, age, race and education level are 
considered to be the predictors and moderators of the relationship between organisational culture and other organisational outcomes (DeNisi and Griffin, 2008; Wee et al, 2014).

The results of this study indicate that there are significant differences between the variable race group and the constructive organisational culture dimension. The coloured employees in this organisation perceive the organisational culture as constructive in nature, compared to other race groups. They see the culture as encouraging them to interact with others and approach tasks in the manner that will help them meet their higher-order satisfaction needs (Cooke and Szumal, 2000). The results of this study also indicated significant differences between the variable age group and the constructive organisational culture dimension. Young employees in this organisation perceive the organisational culture to be constructive in nature; suggesting that it is characterised by achievements, self-actualising, humanistic-encouraging and affiliation (Cooke and Szumal, 2000). These findings on race and age differences support the results of a study conducted by Martins and Von der Ohe (2006) indicating that the various race and age groups experience the organisational culture dimensions differently; hence they seem to modify the values in the organisation to reflect their own distinct situation.

In terms of the variable job level; the results of this study indicate that managers and operational staff have significant differences regarding the organisational culture dimensions passive/defensive and aggressive/defensive. These results confirm that various levels of the organisation's hierarchy have different views of the organisational culture; where the perceptions of managers are different from the operational staff (Robbins, 2005; Harris and Ogbonna, 1998). These differences occur because employees are individuals and the circumstances surrounding each employee and situation can and will differ vastly; hence the perceptions of the organisational culture can also differ vastly. In relation to the findings of this study, Earley and Mosakowski (2000) indicated that within culturally homogeneous groups, employees will have a tendency to communicate with each another more often and in a greater variety of ways; because they share worldviews and a unified culture resulting from in-group attachments and shared perceptions. These generate individual behaviours such as solidarity with others in a race- or genderbased group; as a result employees conform to the norms of their own group and they display discrimination towards out-groups (Tajfel and Turner, 1985; Ivancevich et al, 2005; Werner, 2007).

In a military organisation, as well as in many other high-risk domains there are well established human resource management and organisational development programmes for employees. However, the results of this study indicate that there are significant differences among employees regarding their perception of the organisational culture; it is therefore recommended that leaders and practitioners in this organisation initiate a diversity training programme. The training programme will create awareness of the current individual differences in the organisation. This practical recommendation can be helpful to employees within the organisation to be able to value diversity where teams are multicultural and the work is complex or high risk in nature. This will ultimately prevent the development of sub-cultures in the organisation due to individual differences.

\section{CONCLUSIONS}

This study was motivated by the need to manage diversity resulting from the organisational landscape where a diverse workforce is the rule rather than the exception. Hence the aim of this study which was achieved was to determine whether individual differences influence employees' perceptions of the organisational culture. The results show that there are significant differences regarding the perception of the organisational culture based on race, age and job level in the organisation. This study provides evidence that individual differences influence perceptions of the organisational culture, and suggests that these differences must first be systematically delineated and understood before effective diversity management interventions can be designed in an organisation.

The first limitation is that the present study used a cross-sectional design which minimizes any possibilities of drawing conclusions regarding the direction of the relationship under study. Secondly, the hypothesis of this study was tested on a sample of employees from one organisation; specifically a military organisation. The fact that this study consisted of participants from one organisation limits the generalization of this findings to other contexts. In addition, the Organisational Culture Inventory (OCI) is based on participants' perceptions and it could have been influenced by confounding variables that were beyond the scope of this study. 
It is therefore recommended that future research investigation should use longitudinal designs in order to achieve a temporal separation of the relevant variables which are predictors, moderators and outcomes. It would also be valuable in terms of future research to conduct a similar study in another organisational context; in order to enhance the theoretical knowledge about individual differences, diversity management and organisational culture.

\section{AUTHOR INFORMATION}

Professor Ophillia M. Ledimo is the head of the Department of Industrial and Organisational Psychology at the University of South Africa (UNISA). She has published numerous accredited articles in refereed journal and proceedings. She is the section editor of the South African Journal of Industrial Psychology. She has presented papers at national and international conferences and is a registered Industrial Psychologist. She holds a DLit et Phil from the University of South Africa. Email:manetom@unisa.ac.za

\section{REFERENCES}

Arnold, J. (2005). Work Psychology:Understanding Human Behaviour in the Workplace. (4th ed). London. Prentice Hall Financial Times.

Bagraim, J. (2007). Motivating the South African Workforce. In A. Werner. (Ed). Organisational behaviour: A contemporary South African Perspective. Pretoria. Van Schaik Publishers. pp 69 - 98.

Brown, A. (1998). Organisational Culture (2nd ed.). London. Financial Times Pitman Publishing.

Cooke, R. A. \& Lafferty, J. C. (1989). Organizational culture inventory. Plymouth, MI Human Synergistics.

Cooke, R.A. \& Lafferty, J.C. (1987). Measuring norms and expectations with the OCI:. Organizational culture inventory, leader's guide. ( $2^{\text {nd }}$ ed.) Plymouth.MI: Human Synergics.

Cooke, R. \& Szumal, J. (2000). Using the Organizational Culture Inventory to Understand the Operating Cultures of Organizations. Thousand Oaks, CA: Sage Publications.

Cummings, T. G. \& Worley, C. G. (2005). Organisational development and change. Thompson, Ohio.

Davidson, G.M. (2003). The relationship between organisational culture and financial performance in a South African Investment Bank. Unpublished Masters Dissertation. University of South Africa. Pretoria.

Deal, T. E. \& Kennedy, A. A. C. (1982). Corporate cultures. The rites and rituals of corporate life. London, Addison-Wesley.

DeNisi, A.S. \& Griffin, R.W. (2008). Managing Human Resources. ( $3^{\text {rd }}$ eds). Boston, MA:Houghton-Mifflin

Earley, P.C. \& Mosakowski, E. (2000). Creating hybrid team cultures: An empirical test of transnational team functioning. Academy of Management Journal, 43, 26-49.

Gilbert, J. A.; Stead, B. A. \& Ivancevich, J. M. (1999). Diversity Management: A New Organizational Paradigm. Journal of Business Ethics, 21, 61-76.

Handy, C. B. (1985). Understanding Organizations. Harmondsworth. Penguin.

Hampden-Turner, C. (1990). Corporate Culture: From vicious to virtuous circles. London. Economist Books.

Harris, L.C. \& Ogbonna, E. (1998). A three perspective approach to understanding culture in real organisation. Personnel Review, 7 (2), $104-123$.

Hofstede, G. (1991). Cultures and Organizations: Software of the mind. Maidenhead. McGraw-Hill.

Ivancevich, J. M.; Konopaske, R. \& Matterson, M. T. (2005). Organisational Behaviour and Management. ( $7^{\text {th }}$ ed). Boston. McGraw-Hill. Irwin.

Johnson, G. 1990. Managing Strategic Change: The role of symbolic action. British Journal of Management, 1 (1), $183-200$.

Kerlinger, F.N. (1986). Foundations of Behavioural Research. ( $3^{\text {rd }}$ ed). New Jersey. Winston Inc.

Lok, P.S. \& Crawford, J. (1999). The relationship between commitment and organisational culture, sub-culture leadership style and job satisfaction in organisational change and development. Leadership and Organisational Development Journal, 20 (7), 365 - 373.

Lumley, E. J. (2009). Exploring the relationship between career anchors, job satisfaction and organisational commitment. Masters Dissertation. University of South Africa. Pretoria.

Manetje, O. \& Martins, N. (2009). The relationship between organisational and organisational commitment. Southern African Business Review, 13 (1), 87 - 111. 
Martins, N. \& Martins, E. (2003). Organisational Culture. In S P Robbins; A Odendaal, G Roodt (Eds), Organisational Behaviour: Global and Southern African Perspectives. Cape Town: Pearson Education South Africa, 379 - 400.

Martins, N.; Martins, E. \& Tereblanche, F. (2004). An organisational culture model to stimulate creativity and innovation in a university library. Advances in Library Administration and Organisation, 21, 56 -69.

Martins, N. \& Von der Ohe, H. (2006). Detecting sub-cultures in an organisation. Southern African Business Review, 10 (2), 130 - 149.

Martin, A. \& Roodt, G. (2008). Perceptions of organisational commitment, job satisfaction and turnover intentions in a post-merger South African tertiary institution. South African Journal of Industrial Psychology, 34 (1), $23-31$.

Mazur, B. (2010). Cultural Diversity in Organisational Theory and Practice. Journal of Intercultural Management, 2 (2), 5-15.

Muteswa, R. \& Ortlepp, K. (2011). Contributing factors to potential turnover in a sample of South African management-level employees. Acta Commercii, 11, 13 -29.

O’Reilly, C. A., Chatman, J III. \& Caldwell, D. F. (1991). People and organizational culture: A profile comparison approach to assessing person-organization fit. Academy of Management Journal, September, 487 - 516.

O’Reilly, C.A.; III, Williams, K.Y. \& Barsade, W. (998). Group demography and innovation: Does diversity help? Research on Managing Groups and Teams, 1,183-207.

Preissing, D. \& Loennies, F. (2011). Organizational Culture and Integration of Older Employees: The German Experience. Journal of New Business Ideas \& Trends, 9 (1), 28-42.

Robbins, S.P. (2005). Organisational behaviour. (11 ${ }^{\text {th }}$ ed). New Jersey, Prentice Hall.

Schein, E. H. (1985). Organizational culture and leadership: A dynamic view. San Francisco. Jossey-Bass.

Scholtz, C. (1987). Corporate culture and strategy - the problem of strategic fit. Long Range Planning, 20 (4), 78 87.

Struwig, F. W. \& Smith, E. E. (2002).The relationship between organisational culture and strategy formulation in South African firms. South African Journal of Business Management, 33 (1), 21-29.

Tanova, C. \& Holtom, B. C. (2008). Using job embeddedness factors to explain voluntary turnover in four European countries. The International Journal of Human Resource Management, 19 (9), 1553 - 1568.

Tajfel, H. \& Turner, J. (1985). The social identity of intergroup behavior. Chicago: Nelson- Hall.

Terre Blanche, M. \& Durrheim, K. (1999). Research in practice: applied methods for the social sciences. Cape Town. University of Cape Town Press.

Thomas, R.R. (1996). Redefining Diversity. New York: American Management Association.

Wee, S., Jonason, P. K. \& Li, N. P. (2014). Cultural differences in prioritizing applicants attributes when assessing employment suitability. European Journal of Work and Organisational Psychology, 23 (6), 946 - 956.

Werner, A. (2007). Organisational behaviour: A contemporary South African perspective (2nd ed.). Pretoria. Van Schaik.

Wrech, J. (2005). Diversity can be bad for you. Race \& Class, 46 (3), 73-84.

Xenikou, A. \& Furnham, A. (1996). A correlational and factor analytic study of four questionnaire measures of organizational culture. Human Relations, 49 (3), 349-372. 